29 (I6I I)

\title{
Observations on anaphylaxis in lower monkeys.
}

\section{By HaNs Zinsser.}

[From the Department of Bacteriology, College of Physicians and Surgeons, Columbia University.]

It is always dangerous to apply to any species of animal reasoning or theories deduced from experimental observations upon another species. In no phase of immunological work is such deduction more unjustified than in anaphylaxis where we know that the reactions induced in different species by a reinjection of proteins vary from each other in fundamental, physiological mechanism. It is of course unlikely, therefore, that we can justly draw conclusions from monkey experiments to conditions prevailing in human beings. But some of those who have regarded the occurrence of true anaphylaxis in the human being as at least doubtful, have, at the same time, cited the difficulty of producing anaphylactic reactions in monkeys in analogy. The problem is hardly one warranting a great deal of extensive research, but in connection with other work going on in our laboratory, we have found it important to investigate, for ourselves, the true conditions prevailing in the lower monkeys.

The production of antibodies in monkeys has for some time been a matter of controversy. Uhlenhuth ${ }^{1}$ injected human serum into Macacus rhesus and found that specific precipitins were formed. Berkeley, ${ }^{2}$ in 1913 , reinvestigated this question on Macacus rhesus and on a Java monkey, and found that these animals treated with human, horse or dog sera, receiving four injections of $I$ to 2 c.c. of these sera, produced neither precipitins nor complement fixing antibodies for the antigens used. He does not believe, therefore, that it would be possible to utilize antisera from lower monkeys for the forensic differentiation of human and monkey sera, as suggested by Uhlenhuth.

There has not been a great deal of systematic work published upon monkey anaphylaxis. Yamanouchi ${ }^{3}$ was unable to produce

${ }^{1}$ Uhlenhuth, Kolle and Wassermann Handbuch, Second Edition, 1913, iii, 264.

${ }^{2}$ Berkeley, Univ. of Calif. Publications in Pathology, 19r3, ii, I05.

'Yamanouchi, Compt. Rend. de la Soc. Biol., 1910, lxii, I,000. 
active anaphylaxis in the lower monkeys against horse serum, and found that the serum of the lower monkeys did not sensitize guinea pigs passively. His horse serum injections produced no effects in the monkeys, but in his report there is no analysis of antibody production or other details which would permit one to draw one's own deductions.

As a necessary accompaniment to some other work we were engaged in, we thought it desirable to do a few experiments, worked out in careful detail, on the problem of antibody production and anaphylaxis in the lower monkeys, and we used, for this purpose, two Macacus rhesus, I Macacus cynomolgus, and 2 South American ringtail monkeys which happened to be available in the laboratory at different times.

\section{EXPERIMENT I.}

The first experiment was carried out in order to determine by the most delicate test available to us, namely, the isolated uterus method of Dale, whether or not a single injection of horse serum would produce any degree of hypersensitiveness in a monkey, analogous to that produced by such injections in guinea pigs.

For this purpose this monkey, Macacus cynomolgus, was etherized on March 13,1920 , and the right fallopian tube removed, and mounted in the Dale apparatus, in a 200 c.c. Ringer solution bath. The monkey was sewed up aseptically, and given 3 c.c. of sterile horse serum intravenously after the operation.

After the fallopian tube had begun to show regular rhythmic contractions, as shown in the chart, I c.c. of horse serum, diluted in 10 c.c. of Ringer's, was introduced into the bath, and this process was repeated twice, at about five-minute intervals, in order to make sure of the quantities of horse serum which could be given without eliciting reaction in the uterus of the untreated or normal monkey.

In the interval between March 13 and April 27, intracutaneous skin reactions with 0.2 c.c. of a I-I 5 horse serum dilution were done on March 22, March 30. April I4, and April 22, and titrations of monkey serum were made on the same days, against horse serum, and against anti-horse serum, to determine the formation of antibodies, or the persistence of antigen, respectively. In no 
case was a definite skin reaction obtained, and in no instance was any precipitating antibody discovered. On April 27, the monkey was again etherized and the other fallopian tube removed by operation. The monkey was again sewed up and the removed tube placed in the Dale apparatus as before. The same horse serum instillations were made, again without the slightest effect, as shown by the attached records (see Fig. I).

At the same time, the monkey, as soon as he came out of the ether, was reinjected with 3 c.c. of horse serum, intravenously, without showing the slightest reaction that could be interpreted as anaphylaxis, either immediately or later.

This experiment shows definitely that a single injection of horse serum did not elicit antibody formation or anaphylactic symptoms in a Macacus Cynomolgus.

\section{EXPERIMENT II}

Monkey II, Small Cebus Monkey.-On March 15 received 4 c.c. horse serum intravenously. Skin reaction 0.I c.c. of $\mathrm{I}-5$ dilution of horse serum, intracutaneously, done just before injection, was entirely negative. March 22, skin reaction, negative, 2 c.c. horse serum intravenously, no symptoms, except slight shivering, two soft defecations, tremor in the legs beginning 12 minutes after injection; perfectly well in 30 minutes. April 7 , titration of serum against horse serum shows a faint but distinct ring in the tubes containing the horse serum, dilution of $I-2$, and I-Io. In consequence, on April 8, a skin test was done with 0.05 c.c. of $1-10$ horse serum, which showed slight redness coming on within 3 minutes, surrounded by a small edematous area, which faded out within 30 minutes, and was regarded by several observers as distinctly different from other reactions produced on the monkeys. This was interpreted as a mildly positive reaction.

Immediately after the skin reaction, I.5 c.c. horse serum was intravenously injected. After the injection, seems uncomfortable and abnormally quiet. After 30 minutes, marked redness of the face, and the lower part of the face and lips are distinctly swollen and edematous. This was noticed by several observers, and checked up by our technician who handles these monkeys continuously. This lasted about 2 hours, when it gradually returned to normal. 

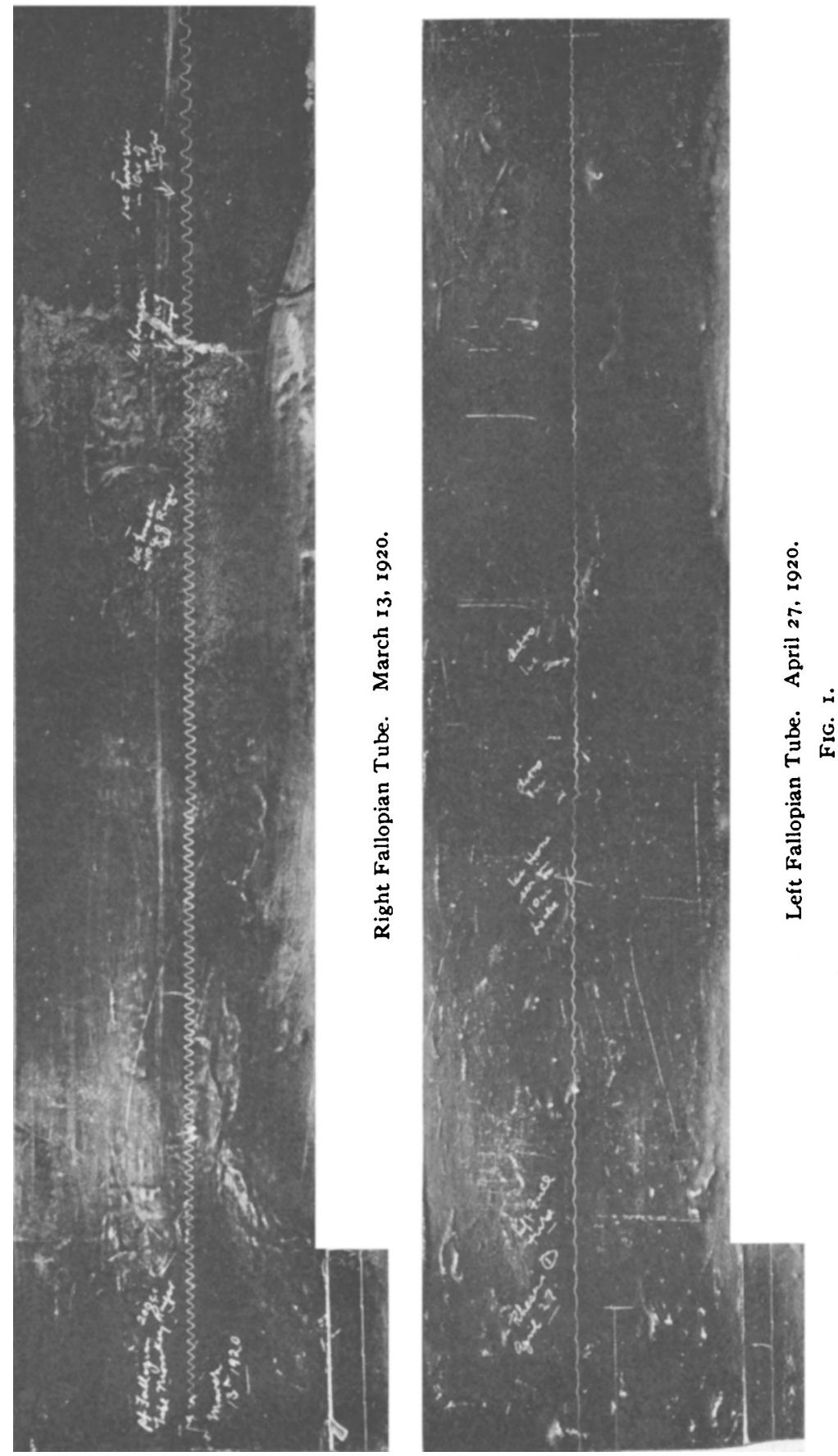
On April 22 this animal was again titrated against horse serum, and distinctly positive ring tests were obtained against horse serum dilutions of $\mathrm{I}-5, \mathrm{I}-\mathrm{I} 0$, extremely faint and hardly noticeable in $\mathbf{I}-20$.

May 5, again titrated with practically the same result, except that reactions were somewhat weaker than on April 22. Skin reaction done on this day shows a doubtful reaction which, however, might have been regarded as a faintly positive one. On this day, 4 c.c. horse serum injected intravenously was followed immediately by shivering, watering of the eyes, and monkey continuously rubs nose and eyes as though they itched. No other symptoms.

In these monkeys, in a considerable number of titrations, the monkey serum titrated against anti-horse rabbit serum showed reactions which seemed positive again and again for sometimes as long as two weeks after the last injection, with appreciable diminution. This made us suspicious of the specificity of the reactions, and we obtained, through the courtesy of Dr. Cecil, specimens of the serum of 7 normal monkeys which we titrated against 4 different specimens of antihorse serum from 4 different rabbits, and found that in almost all cases precipitates were given by antihorse serum against the normal monkey sera in dilutions as high as I-ro. These monkeys all belonged to the Macacus variety, and it was obvious that our apparent antigen persistence was due to a normal reaction between anti horse serum and normal monkey serum. Similar titrations done at the same time against five different normal rabbit sera give only one \pm reaction between normal rabbit " 5 " and normal monkey " 5 ." All other reactions were entirely negative.

Although we cannot explain this, it seemed possible that we might have been dealing with a peculiarity due to unsuspected antigenic relationship between monkey serum and horse serum, a fact which might also possibly explain the failure of the monkeys to react to the horse antigen.

In consequence we shifted further experiments to egg white, instead of horse serum.

Three monkeys were systematically treated with egg white made up in concentrations of $\mathbf{I}-5$, by slaking egg white in salt 
solution and filtering through moist paper. Before these monkeys were injected, their blood serum was titrated to ascertain whether there were non-specific cross reactions between monkey serum and egg white, and no such reactions were obtained. Skin reactions and titrations were done at frequent intervals in the course of the experiments, and were we to detail all of these, we would make a long communication of a relatively simple matter, since there are no technical difficulties in the methods used, sufficiently familiar to all serologists. We will, therefore, omit protocols and state the pertinent results briefly.

Monkey III, Macacus Rhesus.-Preliminary titration showed no reactions with egg white or with anti-egg rabbit serum. An attempt was made to repeat the fallopian tube experiment with this monkey, but owing to the relatively much deeper pelvis of the rhesus variety and the astonishingly small fallopian tube of this young female, the results, although negative, were not convincing and will not be cited.

May 24, 2 c.c., I-5 egg white, intravenously. Intracutaneous skin reaction before this injection, negative.

June I, no antibodies to egg white.

June 17 , skin reaction negative, intravenous injection of IO c.c., 1-5 egg white, no reaction.

July 7 , skin reaction negative; titration shows a very faint positive precipitin reaction against egg albumin, I-Io, and antiegg rabbit serum shows very faint reactions up to dilutions of monkey serum of $\mathrm{I}-5$.

July I2, IO c.c., I-5 egg white, intravenously. Immediate moderate respiratory distress; irregular and rapid breathing within 2 minutes; staggers and turns about as though loss of equilibrium; hind legs weak; holds onto cage; falls down twice, but immediately up again; seems much distressed, but is practically well again in 5 minutes. All of these symptoms took place after monkey had been left alone in cage and effects of handling could be excluded.

July 27 , titration, definite and fairly strong precipitin reaction against egg white in dilution of I-IO. Anti-egg rabbit serum shows no antigen in the monkey serum. Skin reaction on this day, negative; Io c.c. of $\mathrm{I}-5 \mathrm{egg}$ white injected, intravenously; after 5 minutes rapid respiration, great pallor, falls to the ground 
two or three times, but immediately gets up again and keeps himself upright by holding onto the cage. Very distinctly in distress; gradual recovery within Io to 15 minutes.

August I3, skin reaction negative, 7 c.c., I-5 egg white intravenously injected; after 3 minutes is distinctly distressed, respiration very fast; face suddenly very red; legs weak; falls to the ground, but is immediately up again, clinging to the cage; returns to normal after Io minutes.

Monkey IV, Macacus Rhesus.-Young female mate to preceding monkey. This monkey was treated exactly like the preceding. Titrations, skin reactions and injections were run parallel to Monkey III. At no time did we get any indication of positive skin reaction, nor did we, in four separate titrations carried out between May 24 and August I3, ever find the slightest trace of antibody formation. We never obtained, after injection of egg white, reactions comparable to those obtained in Monkey III, nor anything else that could be interpreted as anaphylactic shock.

Monkey V, Brown Ringtail Monkey.-The intention was to prepare this monkey by a number of injections before tests were done on him.

October I5, Io c.c., I-5 egg white, intravenously

October I8, " " " " “ “

October 20, 6" " " " " "

October 26, bled and titrated; no antibody; slight trace of antigen in dilutions up to $\mathrm{I}-\mathrm{IO}$ of the monkey serum.

October 30 , bled and titrated with all necessary controls; no antibody and no antigen in monkey serum, although readings were made up to as long as 48 hours in the ice-chest.

November 5, skin reaction negative. Titration shows no antibody and no antigen; I4 c.c., I-5 egg white injected, intravenously. Within a few minutes shivering and a general tremor of body and limbs; monkey lies down and is weak, very apparently sick; will not eat, and seems to prefer lying on his side when left alone. There are none of the ordinary signs associated in our minds with anaphylaxis, but for 4 to 5 hours after the injection, the monkey allows himself to be handled without much protest, remains lying on his side, and acts generally weak and sick; at the end of 5 hours, he gradually begins to improve, and eats a little bread, and from that time gradually recovers. 
Since, in this monkey, as well as in the preceding ones, we were never able to obtain any considerable amount of antibody, and failed to find antigen in the blood within relatively short periods after injection, we naturally wondered what became of the egg white injected. For this reason we placed this last monkey into a metabolism cage after the last injection, and within 2 hours after the injection of 14 c.c., I-5 egg white, we obtained through a filter-covered funnel, about 12 c.c. of clear urine. This urine was light colored, and neutral to litmus, and was titrated against anti-egg rabbit serum in various dilutions. It gave very heavy and rapidly appearing precipitin reactions against anti-egg rabbit serum in dilutions ranging from concentration to I-Io, and distinctly and visible reactions in dilutions as high as $\mathbf{I}-40$. Parallel titrations against anti-ox and anti-streptococcus rabbit serum, carried out to make sure that we were not dealing with any fortuitous property of the urine which would cause reactions with rabbit serum in general, were entirely negative.

\section{Conciusions.}

In the preceding monkey experiments we have confirmed the observations of a number of workers, especially of Berkeley, that monkeys are very poor animals to use for antibody production and, incidentally, observed that antihorse rabbit serum often gives definite reactions with normal monkey serum.

In the first experiment with a Macacus cynomolgus, carried out by the separate testing of the two fallopian tubes by the Dale method, it appeared that a single injection of horse serum produced not the slightest trace of an anaphylactic sensitization. This was borne out by the results of intravenous injections into the same monkey. No antibodies were formed in this monkey as far as could be ascertained by the precipitin test.

In Monkey II, a small Cebus monkey, and Monkey III, a young female Macacus rhesus, small amounts of antibody were formed after repeated injection, and moderate reactions, probably of an anaphylactic nature, were obtained.

In Monkey II, I 7 days after the second injection of horse serum, a small amount of antibody was found in the serum, and reinjection elicited a reaction which, it seemed to us, as justifiable to 
regard as mildly analogous to human serum sickness, with definite redness and swelling, and some edema of the lower part of the face and lips, lasting about 2 hours. On May 5, 27 days after the third injection, again with small amounts of antibody present in the serum, this same monkey showed nothing but watering of the eyes, and extensive itching of the nose and eyes, with shivering and, otherwise, reactions that could be regarded as slight anaphylactic symptoms if they were observed in human beings.

In Monkey III, treated with egg white, 25 days after the second injection, with slight amounts of antibody present in the serum, a definite reaction was obtained by reinjection of 10 c.c., I-5 egg white intravenously, described in the text under this monkey, unmistakably as a severe reaction of some kind, coming on within 2 minutes, and completely over in 5 minutes. This same monkey I 5 days after the third injection, and 17 days after the fourth injection, always with a small amount of antibody in his serum, manifested similar reactions on each occasion. In Monkey IV and Monkey V, antibodies were never found and no symptoms that could, in any way, be spoken of as anaphylactic, either in nature or in time of occurrence, were observed.

We believe that we are justified in concluding that anaphylaxis is very difficult to obtain in the lower monkeys, probably cannot be obtained by a single preparatory injection, but that occasionally definite mild anaphylactic reactions can be obtained in these animals, in one case simulating some of the symptoms associated in human beings with serum sickness (Monkey II), and in our series this occurred only in monkeys in which small amounts of antibody could be demonstrated.

Why antigen should disappear with relative speed, and no antibodies appear in some of these monkeys, may possibly be explained by the fact that in the last monkey, we observed that, within a few hours, the egg white had passed through the kidney into the urine with remarkable speed.

To some extent our results with the monkeys indicate analogy to conditions in human beings as found by McKensie in his studies upon the parallelism between the antibody curve and serum sickness, but at the same time they show that human beings are considerably better anbitody producers than are the monkeys, and 
if the parallelism between the two conditions is as we surmise, one would expect the greater severity of symptoms which occurs in human beings.

\section{$30(1612)$}

\section{Dissection and injection studies on the Amœba.}

\section{By Robert Chambers.}

[From the Department of Anatomy, Cornell University Medical College, New York City.]

The species used was Amœba proteus. By means of a micropipette liquids of various kinds were injected and the effect noted.

Oils form spherical droplets which are carried about in the cytoplasmic currents. A large drop is usually expelled. Immediately on being extruded the drop tends to flow over the surface of the $A m a b a$ thus partially engulfing it.

Distilled or spring water diffuses through the granular endosarc diluting it. The dilution is followed by a contraction of the endosarc and the massing of a hyaline fluid between the endosarc and the external pellicle of the Amaba. This dilates the area usually termed the ectosarc. The fluid soon accumulates on one side of the $A m \propto b a$ in the form of a blister which is ultimately pinched off.

A number of acid indicators were injected. The color reactions showed that the protoplasm of the Amoba is more acid than its environment. Upon death the colors change to those characteristic of the surrounding medium.

The difference in behavior of living protoplasm to "basic" and to "acid" dyes is striking. The "basic" dyes used were all chlorides of colored basic radicles and the "acid" dyes, potassium or sodium salts of colored acid radicles. In every case the "basic" dyes had a coagulating and the "acid" dyes, a liquefying effect on the protoplasm.

In the case of the "acid" dyes, when the effect is local, the healthy non-colored portion of the endosarc shrinks away from the colored liquefied area. This liquid accumulates under the pellicle in the form of a blister and is ultimately pinched off. 